\title{
Premio Pusterla 2020
}

\author{
Anna Magdalena Elsner
}

SNF Marie Heim-Vögtlin Fellow

Einen Essaywettbewerb für Medizinstudierende sowie die in der Schweiz arbeitenden Ärztinnen und Ärzte während einer Pandemie durchzuführen, das ist nicht unbedingt, was ich mir vorgestellt hatte, als ich den Juryvorsitz des Premio Pusterla 2020 übernahm. Für die Durchführung der Preisverleihung war dies nicht ganz einfach, denn das Herzstück des Premio Pusterla liegt, seitdem der Preis 2018 zum ersten Mal durch das Institut für Biomedizinische Ethik der Universität Zürich ausgeschrieben wurde, in einer öffentlichen Preisverleihung. Im Übereinkommen mit Edio Pusterla, dem grosszügigen Sponsor des Preises, und Institutsdirektorin Nikola Biller-Andorno entwickelten wir ein Online-Format, um die Preisverleihung an die aktuelle Situation anzupassen. Die Preisausschreibung sucht nach Essays, in denen es um ethische Probleme des ärztlichen Alltages geht - Probleme, auf welche ein Medizinstudium oft nur bedingt vorbereiten kann und welche in der Essayform vertieft reflektiert werden können. COVID-19 konfrontiert das Gesundheitswesen mit genau solchen Fragen. Ein Format wie der Premio Pusterla, welcher ebendiesen Fragen Raum gibt, schien uns daher in der jetzigen Situation besonders wichtig. Zweifel standen im Vordergrund der drei Essays, die es ins Finale des Premio Pusterla Junior geschafft hatten, sowie in Andreas Gutzeits Essay, der den Premio Pusterla Senior davontrug. Etymologisch erklärt entspringt der Zweifel einem Zustand des Zwiespalts. Die innere Unentschiedenheit in Bezug auf Fruchtbarkeitsbehandlungen, auf Impfverweigerung, auf den assistierten Suizid sowie die Rolle von ärztlicher Expertise in einer zunehmend technologisierten Medizin charakterisierte die diesjährigen Essays. 1958 hat der Psychiater und Philosoph Karl Jaspers ebendiesen Umgang mit Unsicherheit als Teil des Ethos des Arzt-Seins hervorgehoben. Er schreibt dort:

Der Arzt, der auf Grund des naturwissenschaftlichtechnischen Fortschritts so Unerhörtes kann, wird zum ganzen Arzt erst, wenn er diese Praxis in sein Philosophieren aufnimmt. Dann steht er auf dem Felde der Realitäten, die er kundig gestaltet, ohne sich von diesen Realitäten dupieren zu lassen. Als der stärkste Realist weiss er im Nichtwissen [1].

Genau um dieses Wissen im Nichtwissen ging es unseren Preisträgern. Der Essay als literarische Form, der nicht zu Entscheidungen oder gar zum Handeln

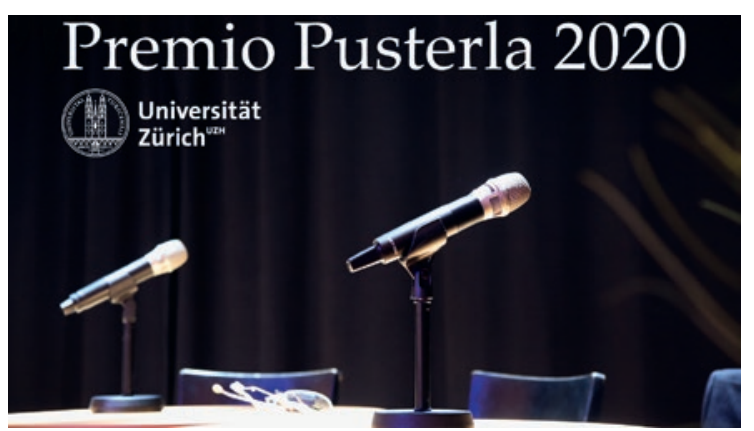

Ein leerer Saal - zum ersten Mal fand die Preisverleihung nur online statt.

Die Preisträger des Premio Pusterla Junior 2020 sind: Noa Kropf mit «Das Impfdilemma», 1. Platz (auf Seite 1161 dieser Ausgabe):

Alyson Gross mit «Es tut mir leid, dass du nicht bleiben konntest», 2. Platz (online unter saez.ch $\rightarrow$ Ausgabe 37/2020);

Amely Walser mit «In Würde sterben, in Würde leben», 2. Platz ex aequo (online unter saez.ch $\rightarrow$ Ausgabe 37/2020);

Der Preisträger des Premio Pusterla Senior 2020 ist: Andreas Gutzeit mit "Der freundliche Halbautomat» (auf Seite 1164 dieser Ausgabe).

zwingt, erlaubt es, Verunsicherungen laut werden zu lassen, die Beständigkeit von Wissen in Frage zu stellen und so den Selbstzweifel als Grundpfeiler einer Ethik des ärztlichen Handelns und Denkens herauszuarbeiten. In einer Situation wie der COVID-19-Pandemie, wo Wissen oft noch fehlt oder unsicher ist, erinnerten die Preisträgerinnen und Preisträger daran, dass ethisches Hinterfragen immer Teil medizinischer Entscheidungsprozesse sein sollte.

Die Preisverleihung fand mit fast 100 virtuellen $\mathrm{Zu}$ schauern am 20. Mai über Zoom statt. Beatrice Beck Schimmer (Direktorin Universitäre Medizin UZH) erteilte ein Grusswort, und die Jury (Brida von Castelberg, Anna Elsner, Christoph Meier) besprach die Siegertexte virtuell. Die Finalistinnen für den Premio Pusterla Junior sowie der Pusterla-Senior-Preisträger wurden in bewährter Weise durch ein Coaching der Literaturwissenschaftlerin und Autorin Hildegard Keller und Bloomlight Productions unterstützt. Ein grosses Dankeschön an alle, die diesen Abend technisch, inhaltlich und finanziell ermöglicht haben. 